\title{
Analysis of the Pulling Effect of Hinterland Economy of Port Logistics
}

\author{
—- Taking Ying Kou Port as an Example
}

\author{
Bao Jianmei \\ School of Economic and Management \\ Shengyang Aerospace University \\ Shengyang, China \\ Baojianmei@sau.edu.cn
}

\begin{abstract}
With the deepening of China's rapid economic development and continuing opening up pattern, port logistics plays an increasingly important role in the internal and external economic situations. As one of the main characteristics of the port economy development, port logistics not only stimulates economic development of the hinterland, but also a measure of the development level of port economy of a country. As port logistics plays an important role in the development of the national economy, and has contributed to the economic prosperity of the country, the promotion of port economy is of great significance to driving the hinterland economy.
\end{abstract}

Keywords-port logistics, ; hinterland economy; SWOT analysis; harmonious development; Yingkou Port

\section{INTRODUCTION}

With the rapid development of international trade, shipping competition is increasingly fierce, and largescale, high-speed container ships have become an irrevocable trend, and the race of ports to develop logistics centers makes competition between port logistics fiercer. The competition that port logistics faces comes not only from the nearby ports but also from the demand of the hinterland economy. First of all, due to the construction of highways, railways and inland waterways transport network in hinterland, the traditional concepts in the hinterland have been broken, and mobility, migration and spread of material are strengthened. A modern port city and its hinterland are economically interlinked and influence and interact with each other. The formation and development of port cities are influenced and constrained by the natural resourcesand socio-economic conditions of hinterland, and the hinterland's economic and social development is inseparable from the port city in terms of economic, technical and other assistance and support. The two are complementary and interactive. Therefore, the development of port logistics is of important significance not only to itself but also to the related economic development of hinterland.

\section{THE GEOGRAPHIC LOCATION OF YINGKOU PORT}

The geographic coordinates of Yingkou Port are east longitude $122^{\circ} 06^{\prime} 00$ ' and north latitude $40^{\circ} 17^{\prime} 42$ ', and the port is the country's major port of integrated transport hub, the nearest sea port in Northeast China and Eastern Inner Mongolia region, largest cargo port in the Northeast region, and a core port in the Liaodong Bayeconomic zone. Yingkou Port is operated by Yingkou Port Group Corporation (hereinafter referred to as company or the company), under the jurisdiction of which are Yingkou port area, Bayuquan port area, fairy island port area, Panjin port area, sea red port area, Suizhong Shihe port area and Huludao Liutiaogou port area. The port completed a handling capacity of 301.07 million in 2012.

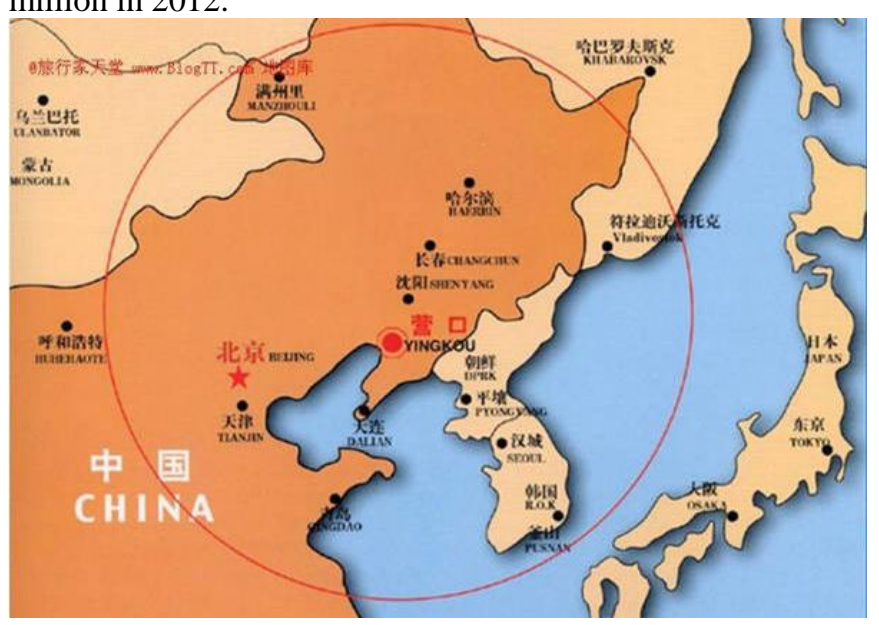

Figure 1. The geographic location of Yingkou Port

\section{THE SWOT ANALYSIS OF YINGKOU PORT'S PORT LOGISTICS}

\section{A. Analysis of the superiority of the port logistics of} Yingkou Port to hinterland's economic development

The geographical position is superior. Yingkou Port is located in the North Temperate Zone, with a temperate maritime climate. In winter, under thermal action, it will not freeze, and when other ports are suspended, it can decentralize logistics pressures, and ensure smooth logistics operations.

Yingkou Port is a sandstone port, fit for construction of deep water wharf, so cargo ships of a ten thousand 
tonnage can pull in to shore to load and unload cargo. Currently, there have been nearly 50 berths built in the port, located at the juncture of economic zone surrounding Bohai Sea and Northeast economic zone.

Economic hinterland is vast. Yingkou Port directly relies on Yingkou, and its direct hinterland is mainly Shenyang economic circle (including Shenyang, Anshan, Fushun, Benxi, Liaoyang, Tieling and Yingkou), and its hinterland covers Liaoning, Jilin and Heilongjiang and four league cities in the east of Inner Mongolian Autonomous Region.

Convenient traffic The port is located at the estuary of Liaohe River in the north of Liaodong Gulf. Shenyang and Dalian Expressway and Harbin and Dalian Highway extend along the port, and Changchun and Dalian Railway directly reaches the front edge of the port. Now, there are more than 20 special container railway lines opened from Yingkou to Harbin, Daqing, Changchun, Dehui, Gongzhuling, Siping, Songyuan, Jiamusi, Mudanjiang and Suifenhe etc, and international special container trains to Europe by way of Manzhouli and to Mongolia by way of Erenhot.

The high efficiency of port logistics Time spent in waiting can be saved. The logistics efficiency of port is influenced by the front edge water depth, number of container berths, effective area of storage yard, total number of skew bridges loaded in containers, the number of operation machines in storage yard and the container passage capacity of the port, and the stronger they are, the higher the efficiency of logistics will be.

\section{B. Analysis of the weakness of Yingkou port logistics in hinterland's economic development}

The scope of business is relatively small. Compared to Dalian Port in the same province, Tianjin Port in Hebei province and other ports, Yingkou Port is still small in scale, which limits its capability to accept extra large orders for transport. The existing routes of Yingkou Port are concentrated in Japan and Korea of Asia, without strong international competitiveness.

Port business scope focuses on high pollutant transport such as coal, ore handling, loading and unloading oil liquid chemicals, which influence the sustainable development of the port. Besides, its passenger routes are mainly concentrated at the national level, limiting the scope of its business.

There are many rivalries. There is competition between Yingkou Port and Dalian Port, Jinzhou Port, Dandong Port and other ports in the province. In terms of scale and expertise, it is disadvantageous compared to the old ports such as Shanghai Port and Tianjin Port.

The port scale and management system are relatively inadequate. As Yingkou Port has just been set up for a short time, the construction of scale and infrastructure is relatively inadequate, and as for management systems, it is still in the exploratory stage, the management of various systems is still relatively immature.

\section{Analysis of the opportunities for Yingkou port logistics in hinterland's economic development}

Through the vigorously support of the government, Liaoning's "5 Points and 1 Line" revitalization planning has been approved as a national strategy, and Yingkou is a key point in the "5 Points and 1 Line" planning. In the north of the urban areas of Yingkou, Liaoning (Yingkou) Coastal Industry Based is constructed, through which Yingkou attracts many famous enterprises settled in, such as China Minmetals Corporation, Anshan Steel Corporation and Panpan Securities Industry Co., Ltd, bringing new opportunities for the development of Yingkou Port logistics. In 2005, Liaoning presented the "6+1" development strategy for the economic zone in Central Liaoning, and Yingkou port is the " 1 " in the strategic mode, which plays the role of an engine the revitalization of Northeast old industrial bases and pulling the economic growth of Shenyang area.

The completion of Yingkou University Park will provide advanced logistics and managerial personnel for the development of port logistics of Yingkou Port, ensuring its future talent needs.

\section{Analysis of the threats of the Yingkou Port logistics to hinterland's economic development}

Dalian, Panjin and Jinzhou ports in Liaoning and Tianjin, Qingdao and Lianyungang ports outside the province are all threats to Yingkou Port to a certain extent, competing for market share with it. Compared to other major ports, the business scope of Yingkou Port is relatively narrow with limited port lines, and its scale and management systems are still incomplete. All of these negative factors have affected the harmonious and sustainable development of Yingkou Port.

Through SWOT analysis, we can see the geographic location of Yingkou port is superior,the traffic there is convenient and its economic hinterland is vast. With high running efficiency of port logistics, it has great potential for development.

\section{ANALYSIS OF THE CORRELATION BETWEEN} YINGKOU PORT LOGISTICS AND HINTERLAND ECONOMY

\section{A. Comparison between the scale of Yingkou port logistics development and the economic growth trend of its hinterland}

Port logistics and the development of regional economy are in a interactive relationship, with mutual effects. On one hand, the development of port logistics can not be separated from the region it is located. Only when the regional economy has developed can port logistics get real development; On the other hand, regional economy makes full use of the advantages of port logistics, promoting its own economic growth. In this paper, the analysis of the relation between Yingkou port logistics and regional economy mainly focuses on the regional economic indicators and the correlation of Yingkou port logistics in promoting hinterland economy.

\section{B. Mathematical model and the selection of sample data}

\section{Selection of mathematical models}

By integrated analysis, preliminarily the linear regression model can be selected for quantitative research on the relationship between port logistics and hinterland economic growth.Unitary Linear Regression Analysis is to use the GDP data of Yingkou and the surrounding hinterland which represents the scale of economy as independent variable,and the cargo handling 
capacity showing the scale of port logistics as dependent variable. This method is relatively simple, which can provide preliminary reference conclusions for the analysis of the correlation between them, used to judge the correlation between the development of port and economic growth of the city.

\section{The selection of sample data}

In this paper, the cargo handling capacity which can demonstrate the logistics scale of ports is selected as the container handling capacity indicator of modern transportation, and the number of containers, especially,can reflect the position of port logistics in economic competition; and for the hinterland economy, the overall GDP reflecting the general level of hinterland economy is selected as its indicator.

\section{The method of linear regression analysis and building of mathematic model}

The building of mathematical model

a) A linear regression equation:

$$
Y_{n}=B_{0}+B_{1} X_{n}+\mu_{n}
$$

Where: $Y$ Yingkou overall GDP (RMB hundred million); ${ }^{X_{t}}$ the observed values of the variables of Yingkou port cargo handlign capacity (hundred million tons); ${ }^{\mu}$ random intervention items (factors other than $\left.X_{t}\right) ; n_{\text {refers to year. }}$

Assuming that the model:

$X$ and ${ }^{\mu}$ are irrelevant.

Random disturbance term ${ }^{\mu}$ obeys the average value zero, and the variance is $\delta^{2}$ in normal distribution, $\left.{ }^{\mu}: n_{(0,} \mu^{2}\right)$

2) Data information: as shown in TABLE I.TABLE II

TABLE I YINGKOU PORT HANDLING CAPACITY IN 2004-2013

\begin{tabular}{c|c|c}
\hline Year & $\begin{array}{c}\text { Yingkou port handling } \\
\text { capacity (hundred million } \\
\text { tons) }\end{array}$ & Growth rate (\%) \\
\hline 2004 & 0.5977 & \\
\hline 2005 & 0.7537 & $26.1 \%$ \\
\hline 2006 & 0.9477 & $25.7 \%$ \\
\hline 2007 & 1.2 & $31.9 \%$ \\
\hline 2008 & 1.52 & $21.6 \%$ \\
\hline 2009 & 1.8 & $18.4 \%$ \\
\hline 2010 & 2.45 & $36.1 \%$ \\
\hline 2011 & 2.87 & $17.1 \%$ \\
\hline 2012 & 3.35 & $16.7 \%$ \\
\hline 2013 & 3.8 & $13.4 \%$ \\
\hline & & \\
\hline
\end{tabular}

TABLE II THE TOTAL GDP OF YINGKOU IN 2004-2013

\begin{tabular}{c|c|c}
\hline Year & $\begin{array}{c}\text { The overall GDP of Yingkou } \\
\text { (RMB billion) }\end{array}$ & Growth rate (\%) \\
\hline 2004 & 307 & \\
\hline 2005 & 381 & $24.1 \%$ \\
\hline 2006 & 458 & $20.2 \%$ \\
\hline 2007 & 556 & $21.4 \%$ \\
\hline 2008 & 703 & $26.4 \%$ \\
\hline 2009 & 806.96 & $14.8 \%$ \\
\hline 2010 & 1002.45 & $24.2 \%$ \\
\hline 2011 & 1200 & $19.7 \%$ \\
\hline 2012 & 1381.20 & $15.1 \%$ \\
\hline 2013 & 1513.1 & $9.5 \%$ \\
\hline
\end{tabular}

\section{Correlation analysis}

The statistical data is used to analyze the handling capacity of Yingkou Port and the total GDP of the surrounding areas, respectively. Thus, the degree of mutual effects and interaction between these port indicators and economic indicators is obtained.

The relation between the handling capacity of Yingkou Port and the GDP of Yinkou and the surrounding areas can be judged by observing the correlation coefficients between the handling capacity of Yingkou Port and the GDP of Yinkou, mainly by using the following formula;

$$
Y_{n}=B_{0}+B_{1} X_{n}+\mu_{n}
$$

$$
\beta_{1}=\frac{n \sum X_{n} Y_{n}-\sum X_{n} \sum Y_{n}}{n \sum X_{n}^{2}-\left(\sum X_{n}\right)^{2}}
$$

$$
\beta_{0}=\sum Y_{n} / n-\beta_{1} \sum X_{n} / n=\bar{Y}-\beta_{2} \bar{X}
$$

Through substituting pf the data in TABLE I.TABLE II into the formula, we get

$$
Y=824.03+35.46507 X
$$

After obtaining the equation through the data, we analyze its relevance, so we first have to obtain the correlation coefficient using the following formula:

$$
r=\frac{n \sum X_{n} Y_{n}-\sum X_{n} \sum Y_{n}}{\sqrt{\left[n \sum X_{n}^{2}-\left(\sum X_{t}\right)^{2}\right]\left[n \sum Y_{n}^{2}-\left(\sum Y_{n}\right)^{2}\right]}}
$$

Substituting data into it, we can get

The correlation coefficients: $R=0.998808906$ $R^{2}=0.9976$

According to the correlation coefficients obtained, we can determine ${ }^{t}$ - the significance of $r$ through inspection, using the following formula: 


$$
t=\frac{r \sqrt{n-2}}{\sqrt{1-r^{2}}}
$$

By substituting the correlation coefficients into the formula, we can get;

$$
\begin{aligned}
& F=1321.256 \quad t=2.072443 \\
& t>t_{0.05(9)} \text { Regression coefficient is significant } \\
& F=1321.256>F \text { O.05(1, 9) The correlation can be }
\end{aligned}
$$

\section{Analysis of measured results}

It can be seen from the above analysis, Yingkou port logistics is closely related to the regional economy. As a window of the development of regional economy, Yingkou port also has to development. The regional economy must first develop, to provide strong support of cargo sources for Yingkou port logistics. Yingkou port logistics and regional economy are highly related.

The economy development of Yingkou and the handling capacity of Yingkou port is intensely related and relevance degree reaches 0.998808906 , which just shows the relationship between port and city. Yingkou port logistics port plays a role of pulling the economy of Yingkou, so there is a close relationship between the economic development of Yingkou and Yinkou port, which should work together to develop.

Through the above calculation, it can be found that there is a strong correlation between the cargo handling capacity of Yingkou Port and the GDP of Yingkou, so the strengthening of the development of Yingkou port logistics can not only pull and promote not only the economic development of Yingkou, but also the hinterland economy of other surrounding areas. They should mutually reinforce and seek coordinative and sustainable development.

\section{RESEARCH ON THE COUNTERMEASURES FOR YINGKOU PORT LOGISTICS AND THE HINTERLAND ECONOMIC DEVELOPMENT}

\section{A. Based on regional advantages, promote the competitiveness of port logistics}

Yingkou Port is one of the earliest foreign trading ports in China, as well as the nearest sea port in Northeast China. It is also an outer port of the central cities in Liaoning, holding jurisdiction over the old Yingkou Port and the new Bayuquan Port. The Bayuquan Port boosts deep water and small waves, not silted or frozen, navigable in the four seasons, which is a good deep water port in North China. Now there are 27 production berths, belonging to two port areas respectively. Yingkou port area has 7 berths, of which 6 are 3000 ton-level berths, and one is 1000-ton-level berth; Bayuquan port area has 20 berths, of which 16 berths are above million tons level, and a 200,000-ton ore dock is being built. The channel depth of Yingkou old port area is $17 \mathrm{~m}$, and it is $27.6 \mathrm{~km}$ long. Bayuquan new port area has $13 \mathrm{~m}$ deep and $13 \mathrm{~km}$ long channels. Yingkou Port is connected to Shenyang-Dalian Expressway, Harbin-Dalian Highway and ChangchunDalian Railway, and Bayuquan port area is $4.2 \mathrm{~km}$ from Shenyang-Dalian Highway,9 kilometers from
Chanchun-Dalian Railway, 210 kilometers from Shenyang in the north, and 190 kilometers from Dalian in the south. Through developed traffic configuration, it is closely connected with the whole northeast region, with excellent ability of collection and distribution of goods. It is the nearest sea port for foreign trade in the Northeast and Eastern Inner Mongolia of China.

With China's economic development and the revitalization of Northeast old industrial policy introduced, especially the Central Liaoning city cluster "6+1" cooperation model introduced, Yingkou Port has enhanced port construction and production, on the road to leap-forward development, making the competitive ability of Yingkou port qualitatively improved.

\section{B. Introduce professional talents; promote harmonious development of Yingkou port logistics}

Under the philosophy of modern logistics, traditional port will become the center of cargo transshipment, gathering, value-adding, assembly and distribution, and control the timely transfer of goods. The quality no longer depends only on the speed of ships entering and leaving the port, the speed and quality of the port in handling cargo, but more and more relies on the quality of its connection with the hinterland and the quality of value-added service, such as logistics and information. In this situation, Yingkou port logistics industry has a long and arduous way to go. It should be based on reality, seizing opportunities, to enhance its core competitiveness in all aspects.

\section{C. mplement policies more flexibly and strongly promote the economic development of Yingkou Port and hinterland}

Strengthen government policy guidance. Through policy guidance, institution-building and other measures, the Government actively provides a good macroeconomic environment to the port logistics development of Yingkou Port. First of all, grasp the developing trend of international container transport and international multi-model transport, make correct orientation for the port, and develop port logistics development policies, to realize the organic integration and effective connection of various management work and links such as land, finance and tax, business and urban management; Second, adjust and optimize the port structure, emphasize the collaboration among various departments, to promote the formation of logistics alliance and provide high quality comprehensive logistics services. Adapt to the needs of hinterland's economic development, and further boost the development of regional economy.

\section{CONCLUSION}

With the economic globalization trend increasingly intensified and international trade fast developing, the development of port logistics is also facing new opportunities, and its development will also lead the development of city and hinterland economy, so the harmonious development of the relation between port and city will become a key factor affecting the economic growth of the port, city and hinterland. Therefore, the research on the countermeasures for the harmonious 
development of port and city relation is of great significance to the sustainable development of port logistics and city economy.

In quantitative aspects, the method of regression analysis is used to measure the relevant degree between port logistics and city economic indicators, and the integrated conclusions obtained are: the correlation coefficients between the cargo handling capacity of Yingkou port and the GDP of hinterland Yingkou and surrounding areas are larger, which suggests that the hinterland economy has a great influence on port logistics. It can be seen there is a great correlation between the development of port logistics and city, which are mutually dependent and promotive and develop together.

Currently, Yingkou Port and Yingkou are developing in a harmonious way, but with the development of economy and the continuous increase of handling capacity of the port, the inharmonious factors between port logistics and the city will emerge. Therefore, for the sustainable development of the harmonious relation between the port and the city, we should learn from experience, make innovation and develop coordinative development tactics so as to lay a solid foundation for the common prosperity of Yingkou Port and hinterland economy.

\section{REFERENCES}

[1] Xu Lei.Analysis of competition tendency between Dalian Port and Yingkou Port in using hinterland sources. Economic Forum $2010(8)$.

[2] Wang Hongli, Han Zenglin. Analysis of connection effect between Yingkou Port and hinterland in Liaoning province. Resources Development and Markets, 201228 (07).

[3] Wang Fang.Analysis of building combined port of Dalian Port and Yingkou Port. Dalian Maritime University Master's thesis, June 26, 2010.
[4] Tang Fu Gu Peiliang, Ren Xuefeng. Empirical analysis on port logistics development in China, business economics and management in November 2011, the 11th issue 169th.

[5] Lin Jingjing, Huang Jing before. Studies on the types of representative port logistics development-inspiration to Xiamen port logistics development. Logistics technology in 2011, 2nd.

[6] Lin, Han Zenglin. Discussion on the developing conditions and strategic measures, Yingkou port. maritime development and management, November 2012.

[7] Zhao Yuanbin. Yingkou port development status and forecast analysis. Modern Economy December 2013 (part one)

[8] Zhang Xin. Development strategy of Yingkou port. Logistics Forum, 2013 9th issue.

[9] Wang Fen, Lei Lei. Summary of research on port logistics. China Water Transport, January 2012 Volume 6 Issue 1.

[10] Wang Chen.Analysis of port logistics development status and countermeasures of Yingkou Port,College of Business Administration graduate thesis of Dongbei University, April 2010

[11] Zhuang Qianwei, Wang Jian. Development and enlightenment of foreign logistics and logistics technology, 2011 Issue 6.

[12] Wang Haiping. Strategic thought on Yingkou Port's developing toward an international hub port. Port Economy, 2011.11.

[13] Cheng Yongjun, Zheng Xiaoxi. Yingkou port's status and role in Northeast container transportation system. Containerization, 2013, the 4th issue, No. 213 in total.

[14] Liang Shuangbo, Cao Youhui, Cao Weidong, Wu Wei. Analysis of Yangtze Delta port logistics economic spatial difference and evolution. Economic Geography, July 2013, Volume 29, Issue 7.

[15] Lin Yushan. Study on the competitive and cooperative development of containers between Dalian and Yingkou ports. Dalian Maritime University Master's thesis, June 2012.

[16] MayerHM.The PortofChicago and the St.Lawerence Seaway[M].Chicago:

University of Chicago,2013.

[17] ayer HM.Current Trends in Great Lakes Shipping[J].Geo Journal,2012,

(2)B117 -122.

[18] Kenyon J.Elements in Interport Competition in the United States[J].Eco-nomic Geography,2010,(46)B1 -24. 